\title{
Alternative vascular graft for extracranial-intracranial bypass surgery: descending branch of the lateral circumflex femoral artery
}

\author{
Mustafa K. BaşKaya, M.D., ${ }^{1}$ Mark W. Kiehn, M.D., ${ }^{2}$ Azam S. Ahmed, M.D., ${ }^{1}$ \\ ÖZKan ATEŞ, M.D., ${ }^{1}$ AND DaVID B. Niemann, M.D. ${ }^{1}$ \\ ${ }^{1}$ Department of Neurological Surgery; and ${ }^{2}$ Department of Surgery, Division of Plastic and \\ Reconstructive Surgery, University of Wisconsin, Madison, Wisconsin
}

\begin{abstract}
Object. Arterial bypass is an important method of treating intracranial disease requiring sacrifice of the parent vessel. The conduits for extracranial-intracranial (EC-IC) bypass surgery include the superficial temporal artery, occipital artery, superior thyroid artery, radial artery, and saphenous vein (long or short). In an aging population with an increased prevalence of vascular disease, conduits for EC-IC bypass may be in short supply in some patients. Herein, the authors describe a case in which the descending branch of the lateral circumflex femoral artery (DLCFA) was utilized as a high-flow conduit for an EC-IC bypass.

Methods. This 22-year-old woman presented with irregular menstrual periods, secondary amenorrhea, and hypothyroidism. A giant intrasellar and suprasellar mass was found. Angiography confirmed a $3.5 \times 2.1-\mathrm{cm}$ fusiform aneurysm involving the cavernous and supraclinoid segments of the right internal carotid artery. A suitable radial artery conduit was not available. The DLCFA was harvested and anastomosed between the $\mathrm{M}_{2}$ segment of the middle cerebral artery and the external carotid artery.

Results. Durable clinical and angiographic results were apparent at the 2-month follow-up.

Conclusions. The DLCFA's diameter and length were used successfully in a high-flow EC-IC bypass surgery. The DLCFA may be a good alternative to radial artery and saphenous vein grafts for an EC-IC bypass requiring high flow. (DOI: 10.3171/FOC/2008/24/2/E8)
\end{abstract}

\section{KEY WoRDS • arterial graft • bypass - cerebral revascularization • lateral circumflex femoral artery}

A FTER the first report of a successful cerebral revascularization procedure performed by Yaşargil et al. ${ }^{21}$ EC-IC bypass surgery gained popularity. This bypass surgery remains an important component in the treatment of medically refractory ischemic neurological diseases, skull base tumors involving the carotid artery, and complex intracranial or extracranial aneurysms. The principles of the EC-IC bypass include careful patient selection with the proper indication for surgery, matching flow to the patient's requirements, appropriate choice of bypass type (interposition or pedicled), and anastomotic site(s). A thorough review of these factors is beyond the scope of this article. Instead, we focused on the use of a novel interposition graft, the DLCFA, for EC-IC bypass surgery, its place in therapy, and its relationship to other grafts.

Abbreviations used in this paper: $\mathrm{EC}-\mathrm{IC}=$ extracranial-intracranial; ECA = external carotid artery; DLCFA = descending branch of the lateral circumflex femoral artery; ICA = internal carotid artery; $\mathrm{MCA}=$ middle cerebral artery; $\mathrm{MR}=$ magnetic resonance; $\mathrm{OA}=$ occipital artery; $\mathrm{PCoA}=$ posterior communicating artery; STA = superficial temporal artery.
Among the grafts for EC-IC bypass surgery, the most commonly used donor graft is the STA. In current surgical practices, other donor grafts, such as the OA, superior thyroidal artery, radial artery, and saphenous vein, are commonly used. ${ }^{15}$ Of these conduits, only the radial artery and saphenous vein grafts are considered high flow. ${ }^{12}$ Myocardial revascularization studies have demonstrated the superiority of arterial over venous grafts as it pertains to the duration of graft patency. ${ }^{1,5,11,22}$ In an aging population with peripheral vascular and coronary artery disease, suitable high-flow grafts either have been used for alternative purposes or are unsuitable as a direct result of the vascular disease process. This situation has led neurovascular surgeons to search for other suitable donor grafts for this purpose.

The LCFA has been used for vascular free flaps and myocardial revascularization. ${ }^{9,10,16,18}$ This robust vessel originates from the deep femoral artery along with its anastomotic counterpart, the medial circumflex femoral artery. The LCFA has 3 major branches: the ascending, transverse, and descending branches. ${ }^{18}$ The descending branch continues distally, traveling with the femoral nerve to the rectus femoris muscle. It then runs deep to the rectus femoris mus- 


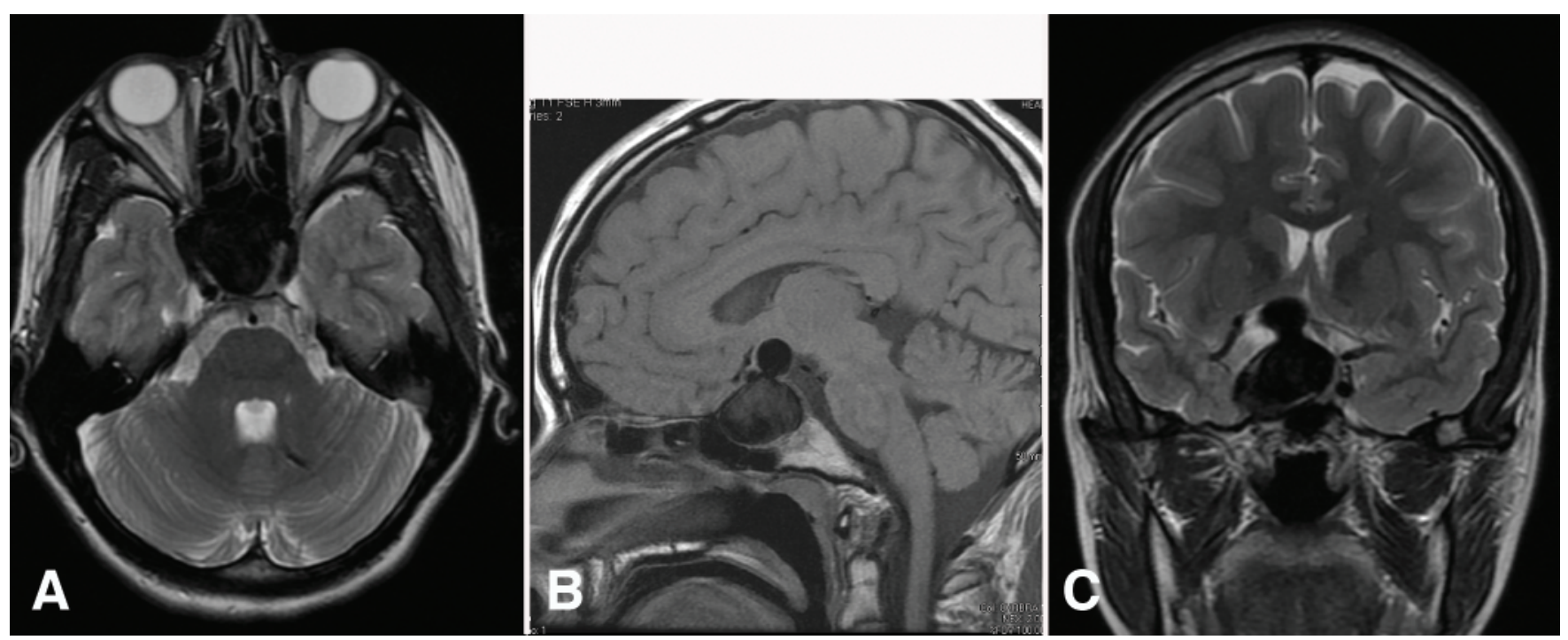

FIG. 1. Axial fast relaxation fast spin echo T2-weighted (A), sagittal T1-weighted (B), and coronal fast relaxation fast spin echo T2-weighted MR images obtained on presentation, showing a bilobed sellar mass with suprasellar extension.

cle and superficial to the vastus lateralis muscle. The vessel branches, at this point, to irrigate the surrounding musculature; however, a large branch continues within the vastus lateralis muscle terminating at the knee by anastomosing with the superior lateral genicular artery.

The descending branch of the LCFA has a large diameter $(2-3 \mathrm{~mm})$, and unlike the radial artery, it does not taper significantly. ${ }^{18}$ In this report we describe the first case in which a DLCFA interpositional graft was used as a highflow graft for flow replacement after vessel sacrifice.

\section{Case Report}

History and Examination. This 22-year-old woman was referred to the neurovascular clinic with a 3-year history of irregular menstrual periods, secondary amenorrhea, and hypothyroidism. An endocrinological workup revealed high levels of thyroid-stimulating hormone $(4.57 \mu \mathrm{IU} / \mathrm{ml})$, prolactin $(81.5 \mathrm{ng} / \mathrm{ml})$, follicle-stimulating hormone $(5.3$ $\mathrm{mIU} / \mathrm{ml})$, and estradiol $(25 \mathrm{pg} / \mathrm{ml})$. Magnetic resonance imaging demonstrated an intra- and suprasellar mass consistent with a vascular lesion (Fig. 1). Cerebral angiography confirmed the diagnosis of a $3.5 \times 2.1-\mathrm{cm}$ fusiform aneurysm emanating from a dysplastic right supraclinoid ICA (Fig. 2). This aneurysm was not amenable to primary surgical clipping or coil embolization. Balloon test occlusion with a hypotensive challenge was performed in preparation for surgical trapping of the aneurysm. Although cerebral angiography demonstrated collateral flow through the PCoA and anterior communicating artery, there was a slight delay of contrast opacification in the right hemispheric venous phase compared with that in the left. The patient did not exhibit any neurological changes during the balloon test occlusion, however.

Operation. A pterional craniotomy was performed, and the aneurysm was trapped between the cervical and supraclinoid ICA proximal to the PCoA. There was no change in the electroencephalography throughout the surgery.
Postoperative Course. On emergence from the anesthesia, the patient demonstrated a dense left hemiparesis. On reexploration, the distal clip was found to be compromising the origin of the PCoA. After removing the clip the hemiparesis improved, and the patient was neurologically intact on discharge. At the 3-month follow-up, the portion of the aneurysm involving the cavernous ICA was thrombosed, but flow remained in the supraclinoid segment of the aneurysm.

Second Operation. Endovascular coil embolization of the residual aneurysm was performed to achieve a Raymond grade of 2 (Fig. 3). On follow-up angiography there was a significant recurrence of the aneurysm due to coil compaction (Fig. 4). To treat the aneurysm definitively, an EC-IC bypass for surgical trapping of the aneurysm was performed. A radial artery graft was unavailable because of the thrombosis after multiple attempts at radial arterial line placement during the first hospitalization and the failure of the Allen test on the contralateral arm. The STA was not considered because it had been partially compromised in the course of a previous craniotomy. A saphenous vein graft would have delivered far greater flow than the patient needed given that some collateral flow was demonstrated angiographically. To transform the flow delivered to the flow required and produce greater patency rates of the arterial conduits, the DLCFA was evaluated with MR angiography, which demonstrated an adequate vessel diameter and length to allow for a high-flow bypass (Fig. 5). Furthermore, this vessel was surgically accessible. An ECA-M ${ }_{2}$ bypass was performed without complication.

Second Postoperative Course. At the 2-month follow-up, the patient demonstrated normal neurological function, and total occlusion of the aneurysm together with patency of the bypass graft was evident on angiography (Fig. 6).

\section{Harvest of the DLCFA}

Harvesting of the DLCFA was performed by M.W.K. 


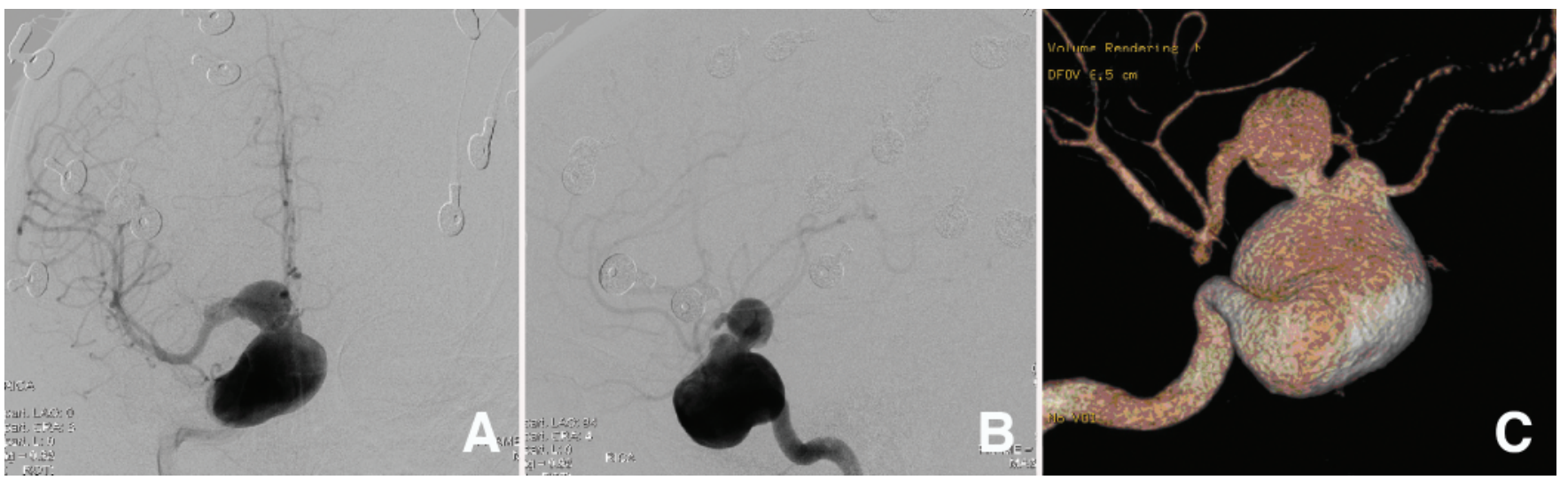

FIG. 2. Preoperative anteroposterior (A) and lateral (B) digital subtraction (DS) angiograms and 3D reconstruction image $(\mathrm{C})$ demonstrating a dysplastic aneurysmal right supraclinoid segment of the ICA.

The DLCFA typically lies between the vastus lateralis and rectus femoris muscles on the anterolateral aspect of the thigh. The space between these muscles can be palpated in thinner patients. A line drawn from the anterior superior iliac spine to the superolateral aspect of the patella predicts the position of the intramuscular septum. An incision was made along this line and dissection is performed through the deep fascia. Arterial branches to the overlying skin can be traced to the artery. Dissection was conducted between the rectus femoris and vastus lateralis muscles until the artery and its accompanying veins were encountered (Fig. 7 upper). In rare circumstances, the artery can be found within the substance of one of the muscles, in which case tracing the skin perforatoring vessels to the source vessel is useful. Arterial branches were ligated with suture ties or a titanium clip. The proximal and distal ends of the artery were ligated and divided (Fig. 7 lower). The thigh was closed in layers over a closed-suction catheter system. The arterial graft was placed in a heparinized solution. Ambulation was permissible on the 1st postprocedure day. No specific restrictions were imposed regarding the use of the thigh.

\section{Bypass Procedure}

The craniotomy and bypass procedure were performed by the senior author (M.K.B.). After a pterional craniotomy, the MCA and its major branches were isolated. The cervical ECA was exposed via the prior incision along the medial side of the sternocleidomastoid muscle. A pediatric chest tub was used to create a preauricular subcutaneous tunnel between the 2 incisions through which the harvested DLCFA was passed. The orientation of the graft was carefully monitored so that the proximal graft would be anastomosed to the ECA and the distal end of the graft would be connected to the intracranial vessel. A small white rubber background was placed under the recipient $\mathrm{M}_{2}$ segment while suturing the anastomosis. With systemic heparinization (2000 U of unfractionated heparin, intravenous), an 1.5- $\mathrm{cm}$ long portion of the $\mathrm{M}_{2}$ segment was trapped with temporary clips. An arteriotomy, $\sim 5 \mathrm{~mm}$ in length, was
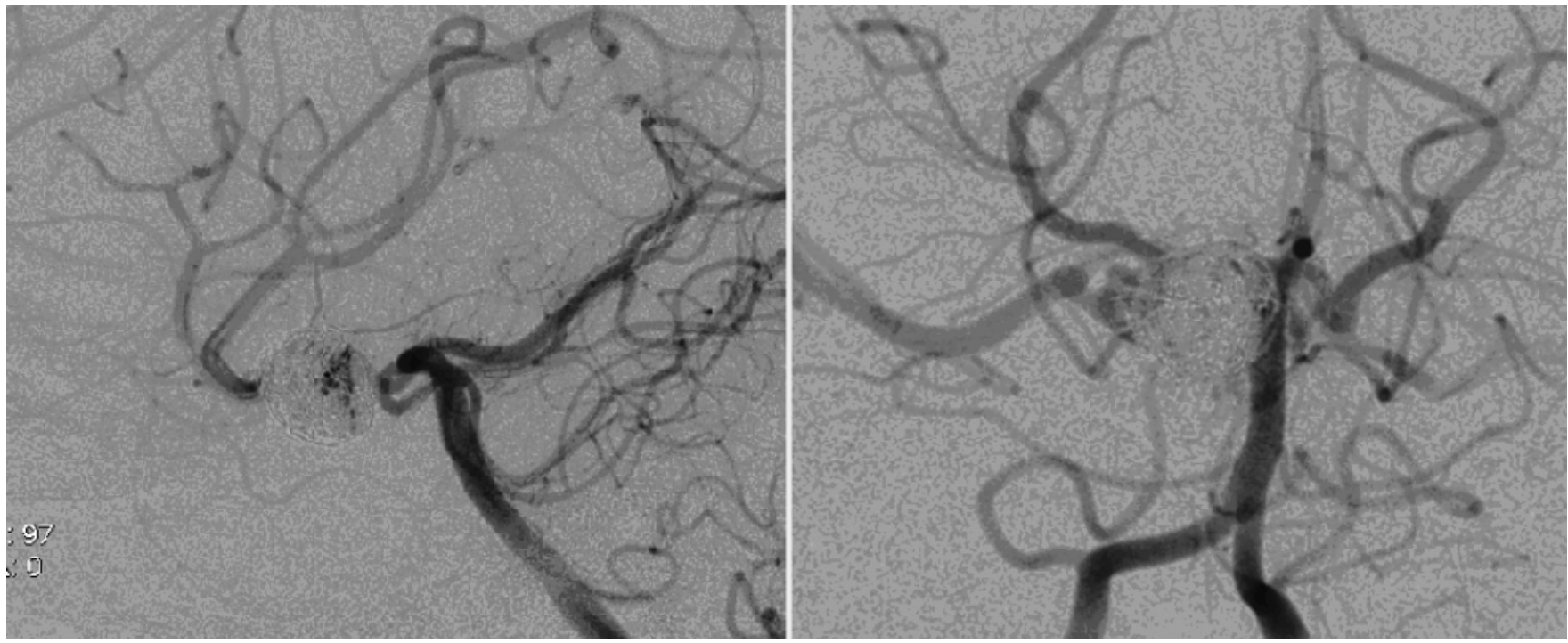

FIG. 3. Anteroposterior (left) and lateral (right) post-coil embolization DS angiograms revealing minimal residual aneurysm. 


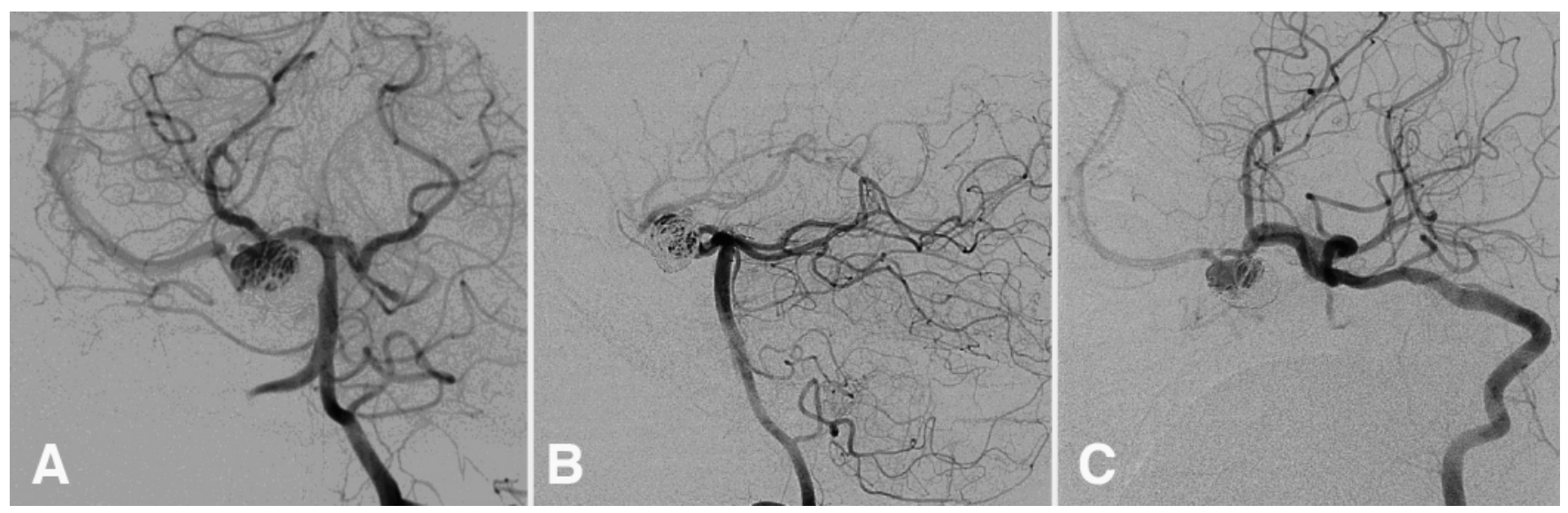

FIG. 4. Anteroposterior (A), lateral (B), and oblique (C) DS angiograms obtained 9 months post-coil embolization, exhibiting aneurysm recurrence.

created. The DLCFA was first anastomosed to the $\mathrm{M}_{2}$ segment with 10-0 nylon sutures. Temporary clips on the $\mathbf{M}_{2}$ segment were released. Back-flow from the $\mathrm{M}_{2}$ segment of the MCA to the graft was observed, and a temporary clip was placed at the proximal end of the graft. The cervical ECA was occluded proximally and distally with temporary clips. After the arteriotomy on the cervical ECA, the DLCFA graft was anastomosed to the ECA with 8-0 nylon sutures. The temporary clips were released, and flow through the graft was assessed with a micro-Doppler flow probe. Topical papaverine was applied over the exposed MCA, its branches, and the anastomosis. The patient was placed on daily regimen of $325 \mathrm{mg}$ aspirin and $240 \mathrm{mg}$ nimodepine for 3 weeks.

\section{Discussion}

Extracranial-intracranial bypass surgery has been used to treat cranial pathophysiologies such as medically refractory ischemic vascular disease and cranial base tumors or complex intracranial and extracranial aneurysms requiring parent vessel sacrifice. Several vascular grafts are available for the EC-IC bypass, including interposition (superior thyroid artery, radial artery, and saphenous vein) and pedicled grafts (STA and OA). Vascular grafts for this bypass procedure are divided into 2 main groups according to their vascular diameter, the prime determinant of flow. ${ }^{12}$ Lowflow pedicled grafts, such as the STA and OA, have small diameters (1.4-1.9 mm, respectively) ${ }^{2,8}$ and serve to augment flow in ischemic vascular disease. High-flow grafts include the radial artery and saphenous vein. These largerdiameter conduits (2.5-3.7 mm, respectively) are suitable for flow replacement in diseases in which the vessel must be sacrificed..$^{19,20}$ Each vascular conduit has benefits and drawbacks depending on the goals of surgery. The STA and OA provide flow augmentation and, in general, do not serve flow replacement for the carotid artery distribution. However, their proximity to recipient vessels presents the advantage of accomplishing bypass surgery via a single incision. The radial artery or saphenous vein, as an EC-IC conduit, can provide much greater flow than a direct pedicled STA and OA distal bypass. When used as an interposition conduit, these vascular grafts require proximal and

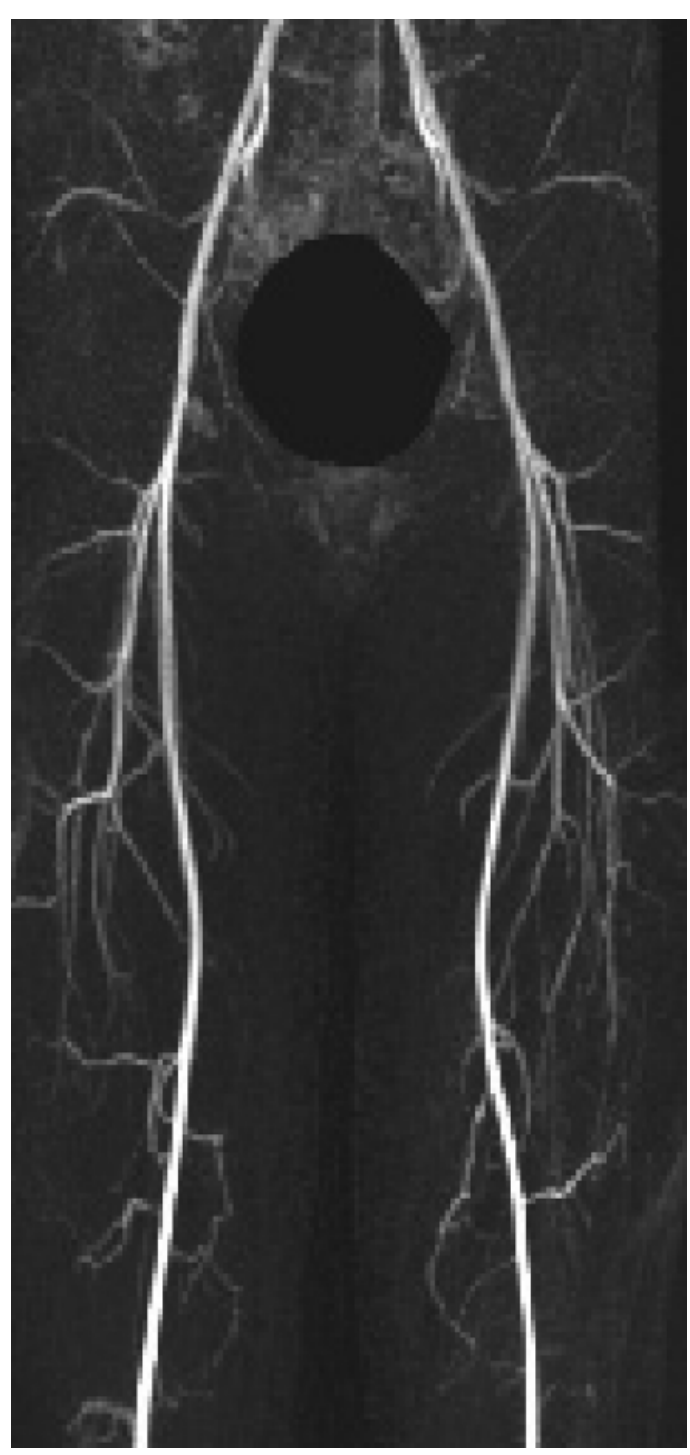

FIG. 5. Magnetic resonance angiogram of the bilateral pelvis and thighs demonstrating the DLCFA. 
Alternative vascular graft for extracranial-intracranial bypass

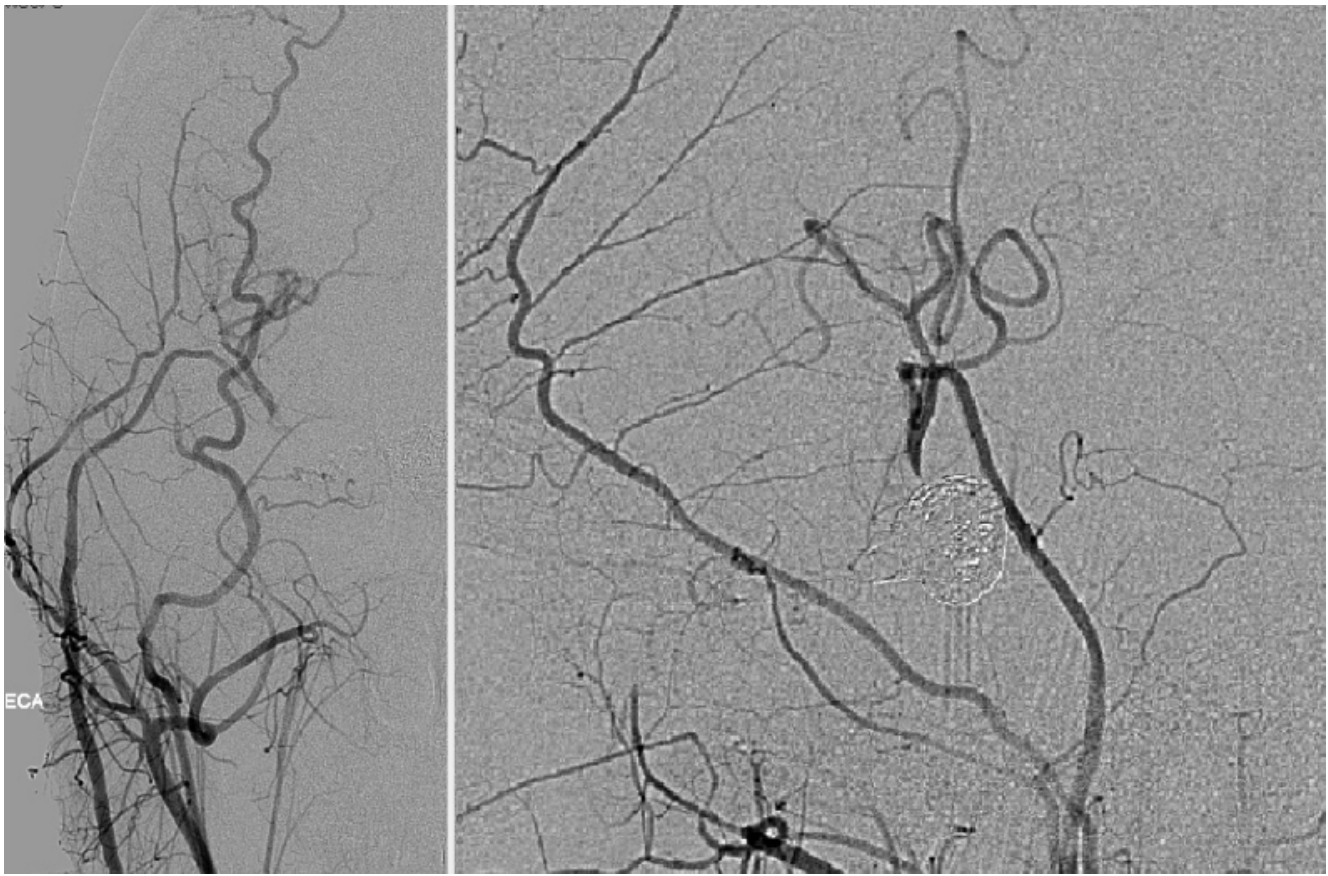

FIG. 6. Anteroposterior (left) and lateral (right) DS angiograms obtained after the EC-IC bypass and trapping of aneurysm, demonstrating a patent ECA- $\mathrm{M}_{2}$ bypass without aneurysm opacification.

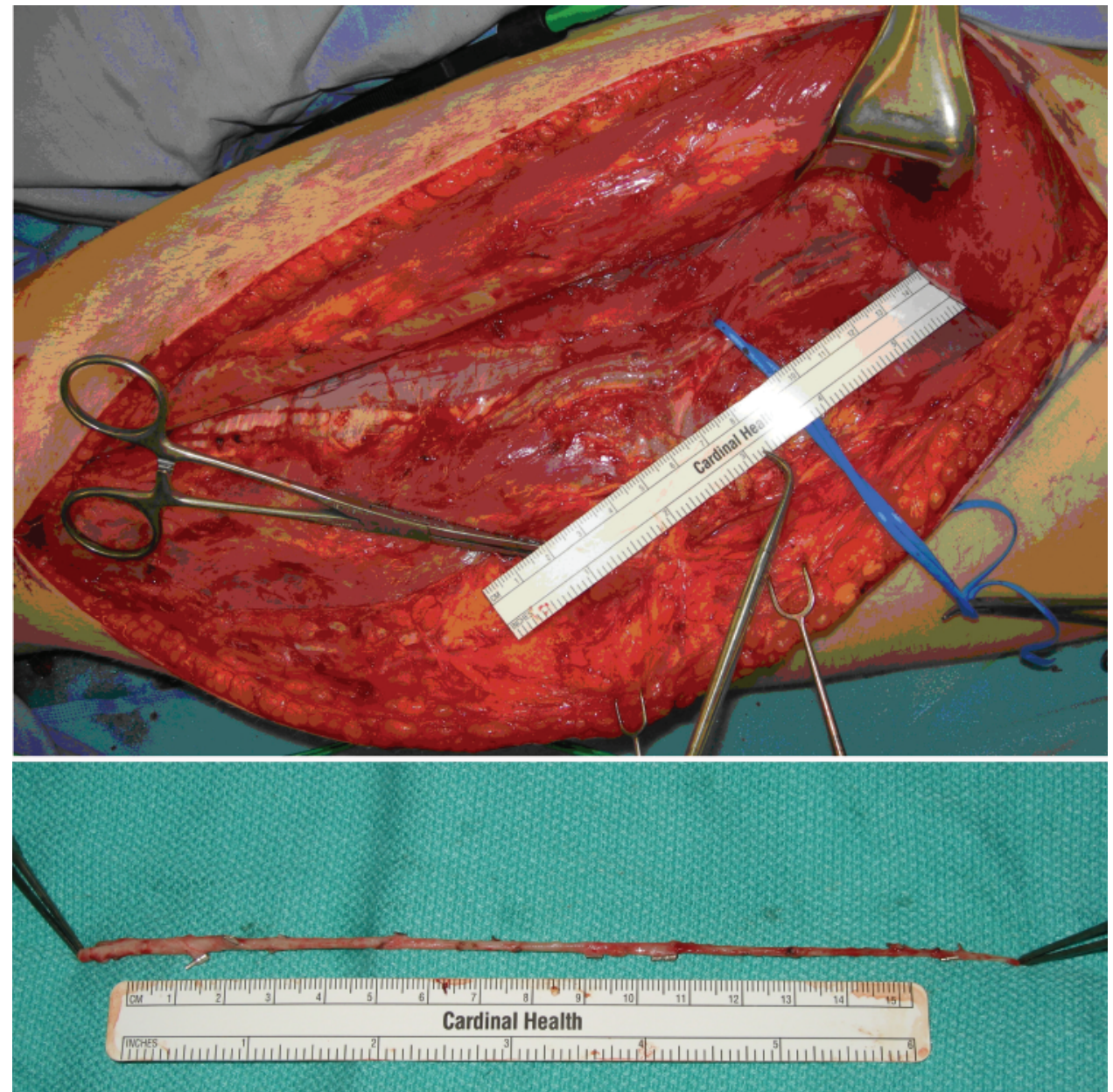

FIG 7. Intraoperative images showing the DLCFA in situ (vascular loop, upper) and as a harvested segment (lower). 
distal anastomoses..$^{14}$ A significant potential disadvantage of free arterial grafts is the occurrence of spasm according to the cardiovascular literature. ${ }^{4}$ This risk is mitigated by the pressure distention technique of Sekhar et al. ${ }^{14}$ Furthermore, based on the cardiac literature, the patency rates of arterial conduits are far superior to those of vein grafts. ${ }^{1,5,6,17,22}$

Arteries that are long, have large caliber, and are expandable are precious to surgeons who perform a vascular bypass. Unfortunately, only a limited number of vessels fit this description. The DLCFA is a potential interpositional graft alternative to the radial artery and saphenous vein. This vessel is a branch of the deep femoral arterial system and arises from the LCFA or as a direct branch of the deep femoral artery. The vessel often maintains a large diameter for much of the length of the thigh or terminates in the proximal thigh. Occasionally, multiple vessels arise from the deep femoral arterial system. Experience with the use of this vessel as a pedicle for microsurgical flaps has led surgeons to apply the vessel to vascular bypass in extremity reconstruction and coronary artery bypass grafting. ${ }^{5,10,13 \text {, }}$ ${ }_{16,18}$ Its use for coronary bypass has been associated with high rates of patency and a low incidence of spasm. ${ }^{5}$ Although the DLCFA may be free of disease, the vessel can serve as an essential route for collateral blood flow to the leg and foot in cases of occlusive disease of the superficial system. ${ }^{7}$ At our institution, MR angiography is used to evaluate these patients and is often performed while investigating the cerebral vasculature. The vessel can also be radiographically examined in patients who undergo conventional cerebral angiography by obtaining a femoral angiogram.

Currently, the only high-flow arterial graft option commonly used in EC-IC bypass surgery is the radial artery. Patients with cerebrovascular disease are likely to suffer from coronary artery and peripheral vascular disease, thus providing unique challenges in discovering suitable conduits for cerebral revascularization procedures. An ideal conduit is $2-3 \mathrm{~mm}$ in diameter, has a nontapered or minimally tapered course, resides at a surgically accessible site, and is long enough to span the extracranial and intracranial anastomotic sites. The DLCFA has a diameter similar to that of the radial artery $(2-3 \mathrm{~mm})$ and a suitable length that can be greater than that of many radial artery grafts (20.7 $\mathrm{mm}) .{ }^{1,3}$ The DLCFA satisfies these criteria and provided a good outcome in the featured case, although the follow-up period was short.

\section{Conclusions}

The DLCFA's diameter and length are adequate for highflow bypass procedures in which other suitable arterial or venous conduits are either unavailable or less desirable. Preoperative vascular analysis is recommended when the surgical plane entails the use of this artery. Patients with suspected arteriosclerosis of the superficial femoral or popliteal arteries should be carefully evaluated.

\section{References}

1. Acinapura AJ, Rose DM, Jacobowitz IJ, Kramer MD, Robertazzi RR, Feldman J, et al: Internal mammary artery bypass grafting: influence on recurrent angina and survival in 2,100 patients. Ann Thorac Surg 48:186-191, 1989

2. Alvernia JE, Fraser K, Lanzino G: The occipital artery: a microanatomical study. Neurosurgery 58 (1 Suppl): ONS114ONS122, 2006

3. Bozbuga NU, Yaymaci B, Kirali K, Güler M, Erentug V, Tas SG, et al: The morphometric features of the lateral circumflex branch of femoral artery as a potential arterial conduit. Turk Gogus Kalp Damar Cer Derg 19:145-148, 2001

4. Dietl CA, Benoit CH: Radial artery graft for coronary revascularization: Technical considerations. Ann Thorac Surg 60: 102-110, 1995

5. Fabbrocini M, Fattouch K, Camporini G, DeMicheli G, Bertucci C, Cioffi P, et al: The descending branch of lateral femoral circumflex artery in arterial CABG: early midterm results. Ann Thorac Surg 75:1836-1841, 2003

6. Faidutti B: Coronary artery bypass grafting with the descending branch of the lateral femoral circumflex artery used as an arterial conduit: is arteriographic evaluation necessary before its use? J Thorac Cardiovasc Surg 117:1229-1230

7. Fukuda H, Ashida M, Ishii R, Abe S, Ibukuro K: Anatomical variants of the lateral femoral circumflex artery: an angiographic study. Surg Radiol Anat 27:260-264, 2005

8. Kawashima M, Rhoton AL Jr, Tanriover N, Ulm AJ, Yasuda A, Fujii K: Microsurgical anatomy of cerebral revascularization. Part I: anterior circulation. J Neurosurg 102:116-131, 2005

9. Koshima I, Fukuda H, Yamamoto H, Moriguchi T, Soeda S, Ohta S: Free anterolateral thigh flaps for reconstruction of head and neck defects. Plast Reconstr Surg 92:421-430, 1993

10. Koshima I, Kawada S, Etoh H, Kawamura S, Moriguchi T, Sonoh $\mathrm{H}$ : Flow-through anterior thigh flaps for one-stage reconstruction of soft tissue defects and revascularization of ischemic extremities. Plast Reconstr Surg 95:252-260, 1995

11. Loop FD, Lytle BW, Cosgrove DM, Stewart RW, Goormastic M, Williams GW, et al: Influence of the internal-mammary-artery graft on 10-year survival and other cardiac events. N Engl J Med 314:1-6, 1986

12. Mohit AA, Sekhar LN, Natarajan SK, Britz GW, Ghodke B: High-flow bypass grafts in the management of complex intracranial aneurysms. Neurosurgery 60 (2 Suppl): ONS105-ONS123, 2007

13. Sakakibara Y, Abe M, Hiramatsu Y, Shigeta O, Ishikawa S, Jikuva T, et al: The descending branch of the lateral femoral circumflex artery for coronary artery bypass grafting. J Thorac Cardiovasc Surg 118:753-754, 1999

14. Sekhar LN, Duff JM, Kalavakonda C, Olding M: Cerebral revascularization using radial artery grafts for the treatment of complex intracranial aneurysms: techniques and outcomes for 17 patients. Neurosurgery 49:649-659

15. Sekhar LN, Kalakovanda C: Cerebral revascularization for aneurysms and tumors. Neurosurgery 50:321-331, 2002

16. Song YG, Chen GZ, Song YL: The free thigh flap: a new free flap concept based on the septocutaneous artery. Br J Plast Surg 37:149-159, 1984

17. Suma H: Arterial grafts in coronary bypass surgery. Ann Thorac Cardiovasc Surg 5:141-145, 1999

18. Tatsumi TO, Tanaka Y, Kondoh K, Minohara S, Sawada Y, Tsuchida T, et al: Descending branch of lateral femoral circumflex artery as a free graft for myocardial revascularization: a case report. J Thorac Cardiovasc Surg 112:546-547, 1996

19. Ulku CH, Ustun ME, Buyukmumcu M, Cicekcibasi AE, Ziylan T: Radial artery graft for bypass of the maxillary to proximal posterior cerebral artery: an anatomical and technical study. Acta Otolaryngol 124:858-862, 2004

20. Ustun ME, Büyükmumcu M, Ulku CH, Cicekcibasi AE, Arbag H: Radial artery graft for bypass of the maxillary to proximal cerebral artery an anatomic and technical study. Neurosurgery 54: $667-671,2004$ 


\section{Alternative vascular graft for extracranial-intracranial bypass}

21. Yaşargil MG, Krayenbuhl HA, Jacobson JH II: Microneurosurgical arterial reconstruction. Surgery 67:221-233, 1970

22. Zeff RH, Kongatahworn C, Iannone LA, Gordon DF, Brown TM, Phillips SJ, et al: Internal mammary artery versus saphenous vein graft to the left anterior descending coronary artery: postoperative randomized study with 10-year follow-up. Ann Thorac Surg 45:533-536, 1988
Manuscript submitted November 15, 2007.

Accepted December 11, 2007.

Address correspondence to: Mustafa K. Başkaya, M.D., Department of Neurological Surgery, University of Wisconsin Hospital, Clinical Science Center, K4/828, 600 Highland Avenue, Madison, Wisconsin. email: m.baskaya@neurosurg.wisc.edu. 